EESTI NSV TEADUSTE AKADEEMIA TOIMETISED. 20. KÖIDE

KEEMIA * GEOLOOGIA. 1971, NR. 1 ,

ИЗВЕСТИЯ АКАДЕМИИ НАУК ЭСТОНСКОИ ССР. ТОМ 20

ХИмИЯ * ГЕОЛОГия. 1971, № 1

удК $552.54: 551.733 . i+551.8$

\title{
МИКРОЛИТОЛОГИЧЕСКОЕ ИССЛЕДОВАНИЕ ИЗВЕСТНЯКОВ ОРДОВИКСКОГО РАЗРЕЗА СКВАЖИНЫ ХААПСАЛУ
}

Работа проведена с целью уточнения условий осадконакопления, выявления группового состава породообразующих организмов, а также вскрытия основных тенденций в развитии изучаемого участка ордовикского моря и его обитателей. С этой целью проделан количественный компонентный анализ (на прозрачных шлифах) известняков из структурной скважины, пробуренной Управлением геологии Совета Министров ӘССР в 1965 году в г. Хаапсалу (Северо-Западная Эстония).

Ордовикские породы вскрыты в интервале $12,0-153,8$, верхняя часть разреза ( $\mathrm{F}_{\mathrm{II}}$ и часть $\left.\mathrm{F}_{\mathrm{I}} \mathrm{c}\right)$ отсутствует. Базальные терригенные отложения $\left(\mathrm{A}_{\mathrm{II}}, \mathrm{B}_{\mathrm{I}}\right)$ детально не изучались. Разрез расчленен, руководствуясь схемой Р. Мянниля (1966), по литологическим данным и распространению отдельных групп фауны, определенных В. Жураплевой (остракоды), Л. Хинтс (брахиоподы) и Х. Стумбуром (наутилоидеи). Горизонты местной стратиграфической шкалы и их подразделения обозначены (в тексте и на рисунке) следующими индексами: $\mathrm{A}_{\mathrm{II}}$ - пакерортский; $\mathrm{B}_{\mathrm{I}}-$ леэтсеский; $\mathrm{B}_{\mathrm{II}}$ - волховский; $\mathrm{B}_{\mathrm{III}}-$ кундаский; $\mathrm{C}_{\mathrm{I}} \mathrm{a}-$ азериский; $\mathrm{C}_{\mathrm{I}} \mathrm{B}-$ ласнамягиский; $\mathrm{C}_{\mathrm{I}} \mathrm{c}-$ ухакуский; $\mathrm{C}_{\mathrm{II}}$ - кукрузеский; $\mathrm{C}_{\mathrm{III}}-$ идавереский с подгоризонтами; $\alpha$ - оямааский, $\beta$ - шундровский; $\mathrm{D}_{1}-$ йыхвиский; $\mathrm{D}_{\mathrm{Ik}}-$ кейлаский с подгоризонтами: $\alpha-$ ристнаский, 6 - лаагриский; $\mathrm{D}_{\mathrm{III}}$ - оандуский; $\mathrm{E}$ - раквереский, где предварительно по структуре и обилию водорослей намечены три части $\left(\mathrm{E}^{1}-\mathrm{E}^{3}\right) ; \mathrm{F}_{\mathrm{I}^{\mathrm{a}}}$ - набалаский с подгоризонтами: $\alpha-$ паэкнаский, $\beta-$ сауньяский; $\mathrm{F}_{\mathrm{I}} \mathrm{b}-$ вормсиский; $\mathrm{F}_{1} \mathrm{c}-$ пиргуский.

На основании детальной характеристики керна скважины были отобраны пробы (для химического анализа и шлифов) не по твердо установленной сетке, а с учетом наибольшей представительности слоев, в среднем 1-2 пробы на метр. Количество проб сокращалось в относительно мощных и однородных слоях известняков верхнего ордовика, а также в доломитовых и мергелевых интервалах. Всего изучено 100 шлифов.

Количественный анализ с подсчетом точек (в среднем 500) на шлифах выполнен по общепринятой методике (см. Jaanusson, 1952). Выделялись частицы диаметрами: менее 0,$01 ; 0,01-0,1 ; 0,1-1,0$ и более 1 мм. Содержание основных компонентов, вычисленное в объемных процентах, вместе с гистограммой содержания нерастворимого остатка (в весовых процентах) изображены на рисунке. Для калькаренитов весьма показательной оказалась кривая медианных диаметров. Точность последней зависит от детальности расчленения промежутка $0,01-1,0$ мм. Поэтому шлам был разделен на две фракцин $(0,01-0,05$ и 0,05-0,1 льм).

Частицы крупнее 0,1 мм были изучены с целью определения групп породообразующих организмов. 


\section{Основные структурные черты известняков}

Bсе встреченные известняки имеют базальный тип цемента и по американской терминологии (Folk, 1959) относятся к микритам. Верхним пределом диаметра частиц основной массы принят, по В. Яануссону (Jaanusson, 1952), размер 0,1 мм. Преобладает микрокристаллическая фракция $(<0,01$ мм) с однородной структурой в чистых и с неоднородной структурой в более глинистых разностях. Оптическое разграничение микрокристаллических кальцита и пелита затруднено и нами не проводилось. Фракция 0,01-0,1 м.м практически чнсто кальцитовая. Это снльно раздробленный шлам неопределимых скелетных образований организмов. В более глинистых известняках встречаются обломочные зерна кварца и полевых шпатов, последние иногда регенерированы, а также аутигенный альбит. В эту же фракцию попадают зерна кукерсита $\left(\mathrm{C}_{I 1}-\mathrm{C}_{\mathrm{III}}\right)$. Названные акцессории отдельно не выделяются.

Аналогично шламу, подавляющее большинство частиц крупнее 0,1 мм представлено кальцитовыми обломками скелетных образований организмов (детрит), реже целыми фоссилиями. В оолитовых известняках $\left(\mathrm{C}_{\mathrm{I}} \mathrm{a}, \mathrm{C}_{\mathrm{I}} \mathrm{b}\right)$ встречаются пропитанные шамозитом частицы детрита, сходные с изображенными В. Яануссоном из нижневируских слоев о. Эланд (Jaanusson, 1960). Из оолитов, содержащихся в количестве $14-16 \%$ только на протяжении 1,4 и поэтому на рисунке не приведенных, встречаются белые (шамозитовые), бурые (гетитовые) и черные (пиритизированные), хорошо известные по работе К. Орвику (Orviku, 1940) и аналогичные оолитам из нижнего ордовика Швеции (Hessland, 1949). В В $\mathrm{B}_{\text {III }}$ встречаются округлые зерна глауконита $(5-11 \%)$ диаметром $0,2-1,0$ мм и единичные окатанные зерна кварца (до 0,3 мм). Обломки пород (гальки и т. п.) в разрезе практически отсутствуют.

Вторичные изменения несущественны. Признаки слабой перекристаллизации части скрытокристаллического цемента замечены в наиболее чистых калькаренитах горизонта $\mathrm{C}_{\mathrm{I}} \mathrm{b}$, в частности в виде регенерации фрагментов иглокожих. Пиритизация в виде микроконкреций $(0,005-$ 0,05 мм) в количестве до $1 \%$ связана с детритом и обусловлена разложением мягких тканей организмов, т. е. происходила примерно одновременно с осадкообразованием. B горизонтах $\mathrm{C}_{\mathrm{III}}-\mathrm{D}_{\mathrm{II}}$ часты примеры окремнения детрита: от единичных пятен опала или халцедона до полного замещения частиц этими минералами. Чаще всего окремнены остатки губок, брахиопод, мшанок, иглокожих, что, возможно, связано с большой первичной пористостью скелетов этих организмов. Обычно окремнено $1-2 \%$ детрита, в исключительных случаях до $37 \%$. Доломитизация в среднем и верхнем ордовике эпигенетическая, происходила вдоль вертикальных зон тектонических нарушений. Доломиты нижнего отдела пластовые, по-видимому диагенетические, поскольку содержат иногда тени детритовой структуры. (Условия залегания доломитов выяснены с учетом данных не только скважин в г. Хаапсалу, но и в его окрестностях, а также геофизических данных.) (Сильнодоломитизированные интервалы, где компонентный анализ первичной структуры невоз-

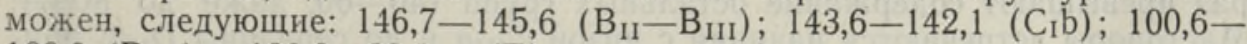
$100,0\left(\mathrm{D}_{\mathrm{III}}\right)$ и $100,0-93,6 \mu(\mathrm{E})$.

\section{Распределение групп породообразующих организмов}

Иглокожие. Остатки скелета иглокожих встречаются уже в доломитах горизонта $\mathrm{B}_{\mathrm{II}}$. До конца лланвирна они остаются преобладающей группой $\left(47 \%\right.$ в $\mathrm{B}_{\mathrm{III}}-\mathrm{C}_{\mathrm{I}}$ a и $61 \%$ в $\left.\mathrm{C}_{\mathrm{I}} \mathrm{b}\right)$. Выше их содержание умень- 
шается, составляя в среднем $20-30 \%$ в $\mathrm{C}_{\mathrm{I}} \mathrm{c}-\mathrm{C}_{\mathrm{III}} \alpha$ и $10-15 \%$ в $\mathrm{C}_{\text {III }} \beta-$ - $\mathrm{D}_{\mathrm{II}}$. В верхах $\mathrm{D}_{\mathrm{II}}$ и в $\mathrm{D}_{\text {III }}$ их несколько больше, в верхнем ордовике их содержание редко превышает $10 \%$.

Б р ах иоподы. Обломки беззамковых найдены в доломитах $\mathrm{B}_{\mathrm{II}}$, а начиная с $\mathrm{B}_{\text {III }}$ встречаются обломки только кальцитовых раковин замковых. Содержание их довольно постоянно - 5-15\%, редко доходит до $30 \%$. Меньше всего (до $5 \%$ ) их в $\mathrm{C}_{\text {III }} \beta$ и верхнем ордовике.

Мшанки впервые появляются в изучаемых шлифах в начале сред- него ордовика $\left(\mathrm{C}_{\mathrm{I}} \mathrm{a}\right)$, а начиная $\mathrm{c} \mathrm{C}_{\mathrm{I}} \mathrm{c}$ и до конца отдела, особенно в $\mathrm{C}_{\mathrm{III}}-\mathrm{D}_{\mathrm{I}}$ (до $70 \%$ ), они - основные породообразующие организмы. В нижней части $\mathrm{O}_{2}$ среди мшанок много обломков мелких инкрустирующих форм, они же слагают большинство шлама. Выше появляются целые колонии и крупные обломки этой группы организмов. В верхнем ордовике количество мшанок резко сокращается $(2-8 \%)$, за исключе.нием $\mathrm{F}_{1}$ с, где их до $30 \%$.

Брахиоподы + мшанки. Объединены мелкие, точно не определимые частицы обеих групп. Вполне вероятно, что здесь в значительной степени преобладают брахиоподы, ибо к ним без колебания можно отнести относительно крупные частицы; сходные по структуре мшанки отличимы благодаря имеющимся и в мелких обломках остаткам перегородок. Содержание этой группы порядка $2-5 \%$, местами $\left(\mathrm{B}_{\mathrm{III}}-\mathrm{C}_{\mathrm{I}} \mathrm{b}\right.$, $\left.\mathrm{D}_{\mathrm{II}}, \mathrm{F}_{\mathrm{I}} \mathrm{c}\right)$ до $10-15 \%$ и даже до $38 \%\left(\mathrm{D}_{\mathrm{III}}\right)$, что указывает на очень сильную измельченность частиц.

Т р и л об и ты существенны лишь в арениге и лланвирне $\left(32 \%\right.$ в $\mathrm{B}_{\mathrm{III}}$; $18-22 \%$ в $\left.\mathrm{C}_{\mathrm{I}} \mathrm{a}-\mathrm{C}_{\mathrm{I}} \mathrm{b}\right)$. Начиная с ухакуского горизонта $\left(\mathrm{C}_{\mathrm{I}} \mathrm{c}\right)$ содержание их резко сокращается до $1-8 \%$.

Oстракоды содержатся в чистых калькаренитах $\mathrm{B}_{\mathrm{III}}-\mathrm{C}_{\mathrm{III}}$ в количестве $1-2 \%$, в глинистых известняках $\mathrm{D}_{\mathrm{I}}-\mathrm{D}_{\mathrm{II}}$ их больше $-3-7$ (до 12 ) \%. Местами в $O_{3}$, особенно в тонкозернистых осадках, их относительно много - до $17 \%$.

Трилобиты + остракоды. Содержание точно не определимых частиц этих двух групп $(1-8 \%)$ обычно равно или превышает содержание «чистых» групп.

Гу убки. Встречаются только разрозненные иглы известковых губок, начиная с верхней половины $\mathrm{C}_{\mathrm{I}} \mathrm{b}$ и до нижней половины $\mathrm{D}_{\mathrm{II}} \beta$. Обычное содержание их $-1-6 \%$, местами до $20-30 \%\left(\mathrm{C}_{\mathrm{I}} \mathrm{c}\right.$, низы $\left.\mathrm{C}_{\mathrm{IHI}}\right)$. В верхнем ордовике не встречаются.

Моллюски содержатся в количестве 5-12 (до 19) \% начиная с горизонта $\mathrm{B}_{\mathrm{III}}$ и до низов $\mathrm{C}_{\mathrm{III}} \alpha$. Выше, до $\mathrm{D}_{\mathrm{II}} \alpha$, моллюски очень редки. $\mathrm{B}$ верхней части $\mathrm{D}_{\mathrm{II}} \beta$ (начиная с пяэскюлаской пачки), в $\mathrm{D}_{\mathrm{III}}$ и $\mathrm{E}^{3}$ ик опять больше $-5-25 \%$ (см. также «Неопределимые частицы»).

В одоросли. Остатки зеленых сифоновых водорослей по структуре отчетливо разделяются на две подгруппы: а) вермипореллы и сходные с ними дазипореллы; б) мастопоры. Появившиеся впервые в $\mathrm{O}_{2}$ вермипореллы ограничиваются здесь только двумя изолированными вспышками $\left(48 \%\right.$ в $\mathrm{C}_{\mathrm{I}} \mathrm{c}, 52 \%$ в $\left.\mathrm{C}_{\mathrm{LI}} \alpha\right)$. В верхнем ордовике они в несколько раз превышают содержание остальных групп (40-60, даже до $80 \%)$. Мастопоры встречаются начиная с низов $\mathrm{C}_{\mathrm{III}} \alpha$ и до середины $\mathrm{D}_{\mathrm{II}} \beta$, причем до $\mathrm{D}_{\mathrm{I1}} \alpha$ они присутствуют в количестве $1-3 \%$, редко до $11 \%$. Заметим, что многочисленные в раквереском горизонте водоросли Cyclocrinites, coхранившиеся, как правило, в виде обозначенных пиритом теневых контуров, не учитывались, поскольку в шлифах они неразличимы.

Н еопределимы е ч а стицы. Обычно они составляют $1-3 \%$ детрита. Относительно большое содержание их обусловлено большой измельченностью детрита. Исключение составляет высокое содержанне 


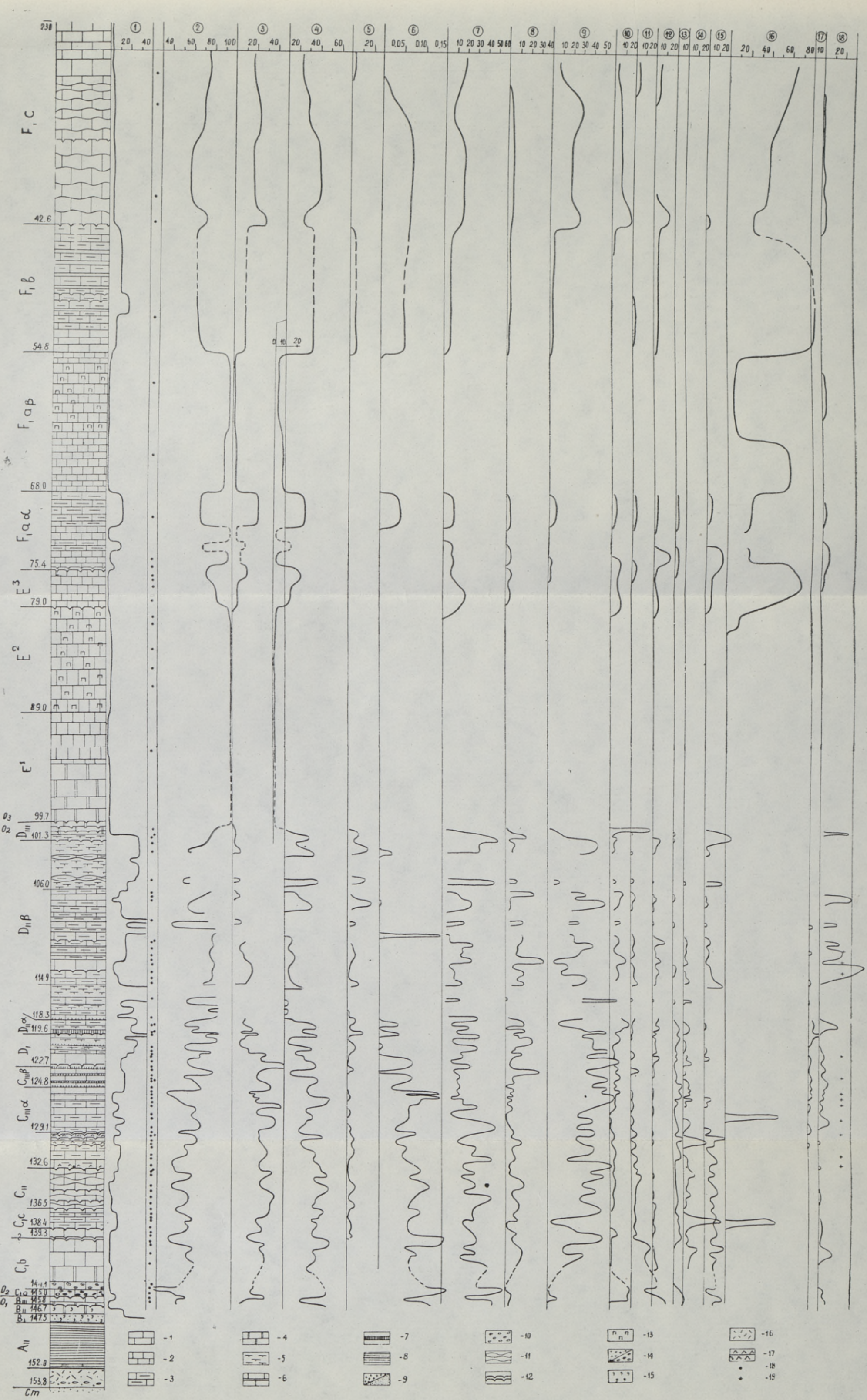

Данные количественного компонентного анализа известняков скважины Хаапсалу.

Номера, обведенные кружком. $1-5$ содержание в процентах от всей породы: 1 - нерастворимого остатка, $2-$ основной массы (<0,1 мм), 3 -

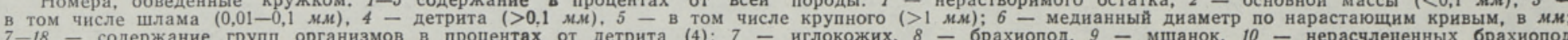
и мшанок, 11 - трилобнтов, 12 - остракод, 13 - нерасчлененных трилобитов и остракод, 14 - известковых губок, 15 - моллюсков, $16-$ водорослей вермипорелла, 17 - водорослей мастопора, 18 - неопределимых частиц. 6 - чередование известняка и мергеля, 7 - метабентонит, 8 - сланец глинистый, 9 - песчаник средне- и мелкозернистый, $10-$ гравелит, 11 комковатая текстура, 12 - поверхности перерыва, 13 - узор пиритизацин, 14 - оолиты бурые и белые, 15 - зерна
ковых, 17 - примесь кукерсита, $18-$ количественно изученные шлифы, 19 - находки лейосферид и тасманитесов. 
неопределимых частиц в $\mathrm{C}_{\mathrm{III}}-\mathrm{D}_{\mathrm{II}} \alpha(3-6 \%)$ и $\mathrm{D}_{\mathrm{II}} \beta-\mathrm{D}_{\mathrm{III}}(20-40 \%)$. Здесь эта группа слагается из первично арагонитовых обломков без определенной структуры и внешней формы. Наиболее вероятно, что это моллюски, не исключено наличие вермипорелл. На рисунке кружками отмечены находки в шлифах органических шариков (лейосфериды, тасманитесы), сконцентрированных на двух уровнях $\left(\mathrm{C}_{\text {III }}\right.$ и $\left.\mathrm{D}_{\text {II }} \beta\right)$.

\section{Некоторые закономерности и выводы}

Характерными для калькаренитов нижней части изученного разреза оказались частые колебания содержания их компонентов при относительном постоянстве пределов и амплитуд этих изменений на продолжении значительных по мощности толщ. Эти колебания, вероятно, цикличны и обусловлены причинами, приведшими к многочисленным перерывам в осадконакоплении. К. Орвику (Orviku, 1940; Орвику, 1960) показал, что для горизонтов $\mathrm{B}_{\mathrm{II}}-\mathrm{C}_{\mathrm{I}} \mathrm{b}$ Северной Эстонии поверхности перерыва часто имеют большое пространственное распространение, т. е. обусловлены колебаниями уровня бассейна. В данном районе отложение чистых калькаренитов началось с $\mathrm{B}_{\text {II }}$ в очень мелководных условиях и продолжалось до $\mathrm{C}_{\mathrm{II}} \alpha$ при постепенном углублении моря, выражавшемся в уменьшении количества поверхностей перерыва, в некотором сокращении количества детрита и среднего диаметра частиц осадка, а также в увеличении содержания терригенной примеси. Донная фауна того времени разнообразна, осадки образовывались преимущественно из организмов с первично кальцитовым скелетом. Содержание детрита в среднем $40 \%$. Сифоновые водоросли, существовавшие, по крайней мере, с $\mathrm{C}_{\mathrm{I}}$, практически не распространились даже в мелководных условиях, что может быть объяснено умеренным климатом.

Последующий этап осадконакопления $\left(\mathrm{C}_{\mathrm{III}} \beta-\mathrm{D}_{\mathrm{III}}\right)$ в изучаемом районе отличался существенным увеличением роли тонкого терригенного материала: в разрезе чередуются мергели и преимущественно глинистые известняки. Детрита здесь меньше (порядка $25 \%$ ), соответственно уменьшается и медианный диаметр частиц осадка. Лучше всего это заметно в начале этапа $\left(\mathrm{C}_{\mathrm{III}} \beta-\mathrm{D}_{\mathrm{II}} \alpha\right)$, которое совпало со временем интенсивной вулканической деятельности в прилегающей геосинклинали. Показателями последней в нашем разрезе являются прослойки метабентонитов.

Из числа основных породообразующих организмов иглокожие сократились почти вдвое, в то время как мшанки, главным образом ветвистые, достигли еще большего расцвета. Факт предпочитания мшанками более глинистых фаций отмечен и в верхнем ордовике CША (Fox, Brown, 1965; Anstey, Fowler, 1969). Р. Л. Ансти и М. Л. Фаулер считают, что переход от известняков к более глинистым осадкам означает, что седи. ментация протекала ниже уровня волнового воздействия, где предпочитали расселяться тонкие ветвистые мшанки, и полагают, что эта глубина не может быть меньше 20 м. Что касается нижнего предела, то в нашем случае нужно учесть, например, следующие признаки: наличие водорослей (если они, конечно, не занесены сюда с отмелей) и опрокинутых полусферических колоний мшанок, указывающих на волнение при штормах. Согласно А. Ронову (1949), можно предположить, что глубина бас. сейна вряд ли превышала 100 м.

Конец среднего ордовика $\left(\mathrm{D}_{\mathrm{II}} \beta-\mathrm{D}_{\mathrm{III}}\right)$ несет следы некоторого обмеления моря: в прослоях известняков увеличивается содержание детрита, в том числе брахиоподового и первично арагонитового детрита; в мерге- 
лях много целых раковин брахиопод и даже прослоев ракушечников. Вывод о мелководности не раз делался и ранее (см., напр., Рыымусокс, Мянниль, 1960) на основании появления несколько восточнее Хаапсалу рифовой фации в $\mathrm{D}_{\mathrm{III}}$, что считается довольно надежным показателем теплого климата (Spjeldnaes, 1961; Данбар, Роджерс, 1962).

Относительно механизма и источников осадкообразования в нижнем и среднем ордовике изучаемого разреза можно полагать, что все осадки (за исключением оолитов и глауконита) образовались за счет смешения только двух компонентов: принесенного с суши терригенного материала и продуктов дезинтеграции (механической, биологической, биохимической) скелетных образований морских организмов.

Начало позднего ордовика $\left(\mathrm{E}^{1}-\mathrm{E}^{2}\right)$ принесло новый, в разрезе Эстонии не встречавшийся, тип осадка - очень чистый известковый ил, практически лишенный детрита и содержащий порой многочисленные тени сифоновых водорослей, считающихся (Høeg, 1936) близкими аналогами современных халимед. Последние, как и ряд других современных зеленых водорослей, обитают на отмелях тропических и субтропических морей (Данбар, Роджерс, 1962; Folk, Robles, 1964; Matthews, 1966) и отмирая распадаются, образуя тонкий ил, накапливающийся в лагунах. Доказано (Stockman и др., 1967), что во Флоридском проливе скорость накопления арагонитового ила, продуцируемого одним видом водорослей, вполне достаточна для образования всей толщи иловых пород этого района. Нет веских причин отказываться от подобного же объяснения условий образования изучаемых нами афанитовых известняков ордовика. Отсутствие известковых оболочек водорослей заставляет предположить преобладание биохимического осаждения, для которого требовалась высокая концентрация извести в воде (Маслов, 1960), что возможно в весьма теплой воде.

Позже $\left(\mathrm{E}^{3}\right)$ появились водорослевые калькарениты и господство сифоновых водорослей распространилось на разные типы осадков, даже глинистых известняков $\mathrm{F}_{1} \mathrm{~b}$. В ашгилле несколько увеличилась роль других организмов, но водоросли остались преобладающей группой до конца изученного разреза.

Полученные литологические данные по одному разрезу наводят на мысль, что наиболее общая тенденция в развитии условий осадконакопления определялась постепенным потеплением климата, что хорошо согласуется с выводами Н. Спьелднэса (Spjeldnaes, 1961).

\section{ЛИ ТЕ Р А Т Р А}

Д ан ба р К., Р д ж е р Дж, 1962. Основы стратиграфин. М.

Ма слов В. Т. 1961. Водоросли и карбонатоосаждение. Изв. АН СССР, Сер. геол., № 12 .

Мянни ль Р. М. 1966. История развития Балтийского бассейна в ордовике. Таллин.

Орвику К. К. 1960. О литостратиграфии волховского и кундаского горизонтов в Эстонии. Тр. Ин-та геол. АН ЭССР, V.

Р с но в А. Б. 1949. История осадконакопления и колебательных движений Европейской части СССР (по данным объемного метода). Тр. Геофиз. ин-та АН CССР, № 3 (130).

Р ы ы усокс А. К., М янниль Р. М. 1960. К палеогеографии ордовика северозападной части Русской платформы. Тр. Ин-та геол. АН ЭССР, V.

A n stey R. L., F ow le r M. L. 1969. Lithostratigraphy and depositional environment of the Eden shale (Ordovician) in the tri-state area of Indiana, Kentucky and Ohio. J. Geol., 77.

Folk R. L. 1959. Practical petrographic classification of limestones. Am. Assoc. Petrol. Geol. Bull., 43.

Folk R. L., Robles R. 1964. Carbonate sands of Isla Perez, Alacran reef complex, Yukatan. J. Geol. 72. 
Fox W. T., B row n J. A. 1965. The use of time-trend analysis for environmental interpretation of limestones. J. Geol., 73.

Hes s l a n d I. 1949. Investigations of the Lower Ordovician of the Siljan district, Sweden. IV. Lithogenesis and changes of level in the Siljan district during a period of the Lower Ordovician. Bull. Geol. Inst. Uppsala, XXXXIII.

$\mathrm{H} ø$ e g O. A. 1936. Norges fossile flora. Paleontologisk Museum Oslo, Nr. 2. Bergen.

$\mathrm{J}$ a a nu s s o n V. 1952. Untersuchungen über die Korngrösse der ordovizischen Kalksteine. Geol. Fören. Förhandl., 74, H. 2.

J a a nus s on V. 1960. The Viruan (Middle Ordovician) of Oland. Bull. Geol. Inst. Uppsala, XXXVIII.

Mat thews R. K. 1966. Genesis of recent lime mud in southern British Honduras. J. Sed. Petrology, 36.

Orviku K. 1940. Lithologie der Tallinna Serie (Ordovizium, Estland), I. Acta et Comm. Univ. Tartuensis. A, XXXVI.

Stockman K. W., G in sburg R. N., Sh inn F. A. 1967. The production of lime mud by algae in South Florida. J. Sed. Petrology, 37.

$S$ p jeld na es N. 1961. Ordovician climatic zones. Norsk Geol. Tidsskr., 41.

\section{Управление геологии}

Совета Министров ЭССР

Поступила в редакцию 16/VI 1970

\section{P. VINGISAAR}

\section{HAAPSALU PUURAUGU ORDOVIITSIUMI LUBJAKIVIDE MIKROLITOLOOGIAST}

Analüüsiti kvantitatiivselt (ōhikutel) 1965, aastal tehtud struktuurpuuraugu südamikn lubjakive, mille tulemusena selgitati algse sette löimis ning settetingimused $\mathrm{ja}$ nende muutused käsitletavas basseini osas. Lubjakivide suhteliselt jämeda (üle $0,1 \mathrm{~mm}$ ) koostis«s - mereorganismide skeletiosakeste - järgi tehti kindlaks peamised setet moodustanud grupid, milleks varases ordoviitsiumis olid valdavalt okasnahksed ja trilobiidi.1. Keskordoviitsiumi mitmekesises pōhjaloomastikus domineerisid sammalloomad koos okasnahksete, käsijalgsete, molluskite ja lubikäsnadega. Hilisordoviilsiumi algul andis kaaneliiva faatsies maad puhtaile lubimuldadele, mis moodustusid tollal väga arvukateks muutunud rohevetikate elutegevuse vői nende lubikestade kuhjumise tulemusena; loomariigi esindajate osatähtsus langes tunduvalt. Neid nihkeid seostatakse esmajärjekorras kliima pideva soojenemisega ordoviitsiumis.

\section{P. VINGISAAR}

\section{A MICROLITHOLOGICAL STUDY OF THE ORDOVICIAN LIMESTONES FROM THE HAAPSALU BORING}

The paper deals with a study of the Ordovician limestones from the borehole of Haapsalu, NW Estonia, in the interval of $12-153 \mathrm{~m}$, between the Quaternary and Cambrian: deposits. In the stratigraphic columns at the left. in the Figure, the local stages are marked, correlated (Мянниль, 1966) to the stages of the universal stratigraphic scheme: $\mathrm{A}_{\mathrm{II}}$-Tremadocian, $\mathrm{B}_{\mathrm{I}}-\mathrm{B}_{\mathrm{Ir}}$-Arenigian, $\mathrm{B}_{\mathrm{III}}-\mathrm{C}_{\mathrm{I}} \mathrm{b}$-Llanvirnian, $\mathrm{C}_{\mathrm{I}} \mathrm{c}-$ Llandeilian, $\mathrm{C}_{\mathrm{II}}-\mathrm{F}_{\mathrm{I}} \mathrm{b}-\mathrm{Cara}$ docian, $\mathrm{F}_{\mathrm{I}} \mathrm{c}$-Lower Ashgillian. The stages $\mathrm{A}_{\mathrm{II}}-\mathrm{B}_{\mathrm{I}}$ are composed of terrigenous rocks, the rest of the section is represented by carbonaceous sediments of a normal sea - by limestones, in particular. The secondary changes in the limestones, apart from some intervals of epigenetic dolomites, are inconsiderable.

The limestones were studied by the point-count method in the thin sections. The position of the thin sections in the profile is indicated by dark circies. The figure illustrates the content of the components (shown by numbers in the circles), in per cent of the total volume of rock; 2 - total matrix (grains les3 than $0.1 \mathrm{~mm}$ ), including mud $(0.01-0.1 \mathrm{~mm}$ ) - 3; 4 - skeletal detritus (coarser than $0.1 \mathrm{~mm}$ ), including 5 - coarse detritus $(>1 \mathrm{~mm})$. Further $(6)$, the median diameter of the sediment is shown, as determined by cumulative curves. On the right, the content of the rock-forming groups of organisms is shown, in per cent of the detritus $(4)$ : echinozoans $(7)$, brachiopods $(8)$, bryozoans $(9)$, indetermined brachiopods and bryozoans (10), trilobites (11), ostracodes (12), indetermined trilobites and cstracodes (13), calcareous sponges (14), molluscs (15), green algae $(16,17)$, undefincd particles (18).

The author presents some palaeogeographical conclusions, and in particular those ccncerning a gradual improvement of the climate from the beginning of the Llanvirnian to the end of the Caradocian, which fact is in good agreement with the global reconstructions by N. Spjeldnaes (1961). 